\title{
Estudio petrográfico y posibles fuentes de los clastos basales de la Formación San Cayetano hacia el sur del Cinturón Plegado de San Jacinto, norte de Colombia
}

\author{
Alejandro Silva-Arias ${ }^{1 *}$; Liliana Andrea Páez-Acuña²; Pedro David Gómez-Gutiérrez; \\ Daniel Andrés Rincón-Martínez ${ }^{1}$
}

DOI: http://dx.doi.org/10.18273/revbol.v41n1-2019001 @ (1)

Forma de citar: Silva-Arias, A., Páez-Acuña, L.A., Gómez-Gutiérrez, P.D., y Rincón-Martínez, D.A. (2019). Estudio petrográfico y posibles fuentes de los clastos basales de la Formación San Cayetano hacia el sur del Cinturón Plegado de San Jacinto, norte de Colombia. Boletín de Geología, 41(1), 15-28. DOI: 10.18273/ revbol.v41n1-2019001.

\section{RESUMEN}

Se considera que los clastos basales de la Formación San Cayetano en el Cinturón Plegado de San Jacinto (CPSJ) evidencian parte de los eventos tectónicos asociados a la interacción de la margen de Sur América con un arco magmático intraoceánico de la Placa Caribe. Dichos clastos provienen del desmantelamiento de un arco intra-oceánico (88-73 Ma), y de la acreción de éste arco al margen continental suramericano; por lo que aportan al entendimiento de la tectónica post-colisional del Caribe Sur. Este estudio está enfocado en el análisis de la diversidad litológica de los clastos en los niveles conglomeráticos basales de la Formación San Cayetano, con el objeto de establecer su fuente y apoyar su procedencia respecto a la configuración de los antiguos sistemas magmáticos existentes en el Caribe colombiano. Los clastos basales al Sur del Alto de Magangué contienen clastos ígneos de afinidad máfica (basaltos con y sin vacuolas, y gabros) y clastos metamórficos (serpentinitas, ortogneis y anfibolitas) de un protolito ultramáfico-máfico. Los clastos de la Formación San Cayetano (Paleógeno Inferior) están relacionados tectónicamente con un ambiente de Arco, que evidencian rápida erosión y un mínimo efecto de transporte (No Disectado a Disectado); por lo que, dichos clastos provienen de fuentes próximas al CPSJ, con una configuración tectónica similar al actual margen NW del Caribe colombiano.

Palabras clave: Clastos; Formación San Cayetano; Cinturón plegado de San Jacinto; Alto de Magangué.

\section{Petrographic study and possible sources of the San Cayetano formation basal clasts to the south of the San Jacinto fold belt, north of Colombia}

\begin{abstract}
It is considered that the basal clasts of the San Cayetano Formation in the San Jacinto Fold Belt (CPSJ) reveal part of the tectonic events related to the South American margin interaction with an intraoceanic magmatic arc of the Caribbean Plate. These clasts come from an intra-oceanic arch dismantling (88-73 Ma), and from arch accretion to the South American continental margin; therefore they contribute to the South Caribbean post-collisional tectonics understanding. This study is focused on clasts lithological diversity analysis in the San Cayetano Formation basal conglomerate levels, in order to establish its source and support its origin respecting to old magmatic systems configuration existing in the Colombian Caribbean. The basal clasts at the south of Magangué High contain mafic affinity igneous clasts (basalts with and without vacuoles, and gabros) and metamorphic clasts (serpentinites, ortogneis and amphibolites) of an ultramafic-mafic protolith. The San Cayetano Formation clasts (Lower Paleogene) are tectonically related to an Arc environment, revealing rapid erosion and a minimal transport effect (Not Dissected to Dissected); therefore, these clasts come from sources close to the CPSJ, with a similar tectonic configuration to the current NW Colombian Caribbean margin.
\end{abstract}

Keywords: Clasts; San Cayetano Formation; San Jacinto Fold Belt; Magangué High.

\footnotetext{
${ }^{1}$ Instituto Colombiano del Petróleo, ECOPETROL S.A., Piedecuesta, Colombia. (*) alejandro.silva@ecopetrol.com.co, pedroda.gomez@ecopetrol.com.co,daniel.rincon@ecopetrol.com.co

${ }^{2}$ Universidad Industrial de Santander, Bucaramanga, Colombia. lilipa0812@hotmail.com
} 


\section{INTRODUCCIÓN}

Para entender la evolución tectónica del Margen Caribe colombiano es necesario estudiar los efectos del inicio de la tectónica de margen activa con la subducción de la placa Caribe bajo la placa Suramericana; en el registro sedimentológico que marcó la existencia de áreas elevadas, la disminución de la distancia entre las áreas fuentes y zonas de depósito, y la sedimentación de unidades sin-tectónicas sobre el margen activo. La unidad más antigua que suprayace discordante el basamento oceánico es la Formación Cansona de edad Cretácico Superior, aunque debido a su poca exposición, composición fina y gran deformación; se consideró analizar a la siguiente unidad supra yacente, la Formación San Cayetano del Paleógeno Inferior, la cual posee una mayor exposición regional y posee una secuencia conglomerática basal proveniente de zonas exhumadas, cuyos clastos permiten analizar la afectación de la tectónica de margen activa en el Margen Caribe colombiano. Según Cardona et al. (2012), un arco magmático intra-oceánico desarrollado durante el Cretácico Tardío (88 y $73 \mathrm{Ma}$ ) sobre materiales de la Gran Provincia Ígnea del Caribe (Kerr et al., 1997), fue acrecionado a la margen continental del Norte de Sur América entre 73 y $60 \mathrm{Ma}$. Dicha acreción produjo la obducción de materiales ofiolíticos, la formación de un cinturón metamórfico de media presión, así como la emersión del Cinturón Plegado de San Jacinto (CPSJ). Posteriormente, la pérdida de soporte del orógeno y la formación de un margen convergente oblicuo, permitieron generar una cuenca post-colisional, cuyo primer llenado es registrado por los sedimentos de la Formación San Cayetano, asociada a sistemas de fan deltas (e.g. Alfonso et al., 2009; Bermúdez et al., 2009). El origen de la unidad conglomerática de gránulos y guijos polimícticos, ubicada a la base de la Formación San Cayetano (e.g. Duque-Caro et al., 1996; Guzmán et al., 2004), registró parte de los eventos tectónicos asociados a la interacción de la margen de Sur América con un arco magmático intraoceánico de la Placa Caribe (Cardona et al., 2012), aportando al entendimiento de la tectónica post-colisional del Caribe Sur. Dicha interacción de eventos tectónicos, puede generar zonas altas y bajas que reciben sedimentos de manera diferencial generando una amplia variedad facial en esta unidad estratigráfica y buena parte de las formaciones suprayacentes. El presente estudio está enfocado en el análisis petrográfico de los clastos presentes en los niveles conglomeráticos de la Formación San Cayetano, con el fin de establecer la fuente de estos materiales y aportar al conocimiento de la evolución tectónica del Caribe Sur colombiano.

\section{MARCO GEOLÓGICO REGIONAL}

El CPSJ se encuentra separado del Cinturón Plegado del Sinú (CPSn) al Nor-Oeste por el Lineamiento del Sinú, y del Valle Inferior del Magdalena (VIM) al Sur-Oeste por el sistema de fallas de Romeral. La cuenca del VIM se subdivide en la sub-cuenca de Plato al Norte y la subcuenca de San Jorge al Sur (Barrero et al., 2007), siendo separadas por el Alto de Magangué (AlMa) en la parte central (altos de El Difícil y Cicuco, y la plataforma de Chimichagua al Sur-este) (FIGURA 1A). El basamento del VIM es considerado una corteza continental integrada por rocas ígneas intrusivas y extrusivas, y rocas metamórficas (INGEOMINAS, 1997). Este basamento presenta una importante similitud con el basamento de la Cordillera Central (Terreno CajamarcaValdivia, sensu Cediel et al., 2003) y el Macizo de Santa Marta (sub-placa de Maracaibo, sensu Cediel et al., 2003) (Vinasco et al., 2006; Cardona et al., 2010; Montes et al., 2010; Spikings et al., 2015). Otras litologías ígneas de edad Cretácico Tardío han sido igualmente reconocidas recientemente en el basamento del VIM (Silva-Arias et al., 2016); mientras que solo presenta un registro de rocas sedimentarias desde el Eoceno (Cerón et al., 2007; Mantilla-Pimiento, 2007), lo que sugiere que el VIM se encontraba emergido para el Cretácico Tardío y Paleógeno Temprano. Por otra parte, el basamento del CPSJ se compone de litologías básicas y ultrabásicas relacionadas con la Gran Provincia Ígnea del Caribe, que están cubiertas por una secuencia sedimentaria que inicia con rocas de ambiente marino (calizas y margas) pertenecientes a la Formación Cansona de edad Cretácico Superior (Duque-Caro, 1973; GEOTEC, 1997; 2003; Guzmán et al., 2004; Guzmán, 2007). La Formación San Cayetano (se incluye su formación equivalente Arroyo Seco) es considerada como de edad Paleógeno Inferior (DuqueCaro et al., 1996; GEOTEC, 1997; Guzmán, 2007) y se encuentra de manera discordante sobre la Formación Cansona, su contacto superior también es discordante, entrando en contacto bien con la suprayacente Formación Maco (Eoceno Medio) en el Arroyo Maco (Paraconforme?), con la Formación Toluviejo (Eoceno Superior) en el Sector de Arroyo Seco, o con la Formación Ciénaga de Oro (Oligoceno) en los sectores de Ciénaga de Oro y Tuchín. En la Formación San Cayetano se documentan dos grandes segmentos: hacia la parte inferior se observan capas medias y gruesas de conglomerados polimícticos matriz-soportados con clastos subredondeados tamaño bloque, con bases erosivas e intercaladas con grandes cuerpos masivos de conglomerados matriz-soportados de gradación inversa. Estos conglomerados varían texturalmente a areniscas de grano medio a grueso y areniscas conglomeráticas 
ocasionalmente con estratificación cruzada planar y en artesa con imbricación de clastos. Esta transición del segmento basal conglomerático a intercalaciones de areniscas y lodolitas, culmina con un nivel superior relativamente espeso de capas gruesas de lodolitas, lodolitas calcáreas gris oscuras y capas delgadas de litoarenitas con ocasional cemento calcáreo, laminación plano-paralela, ondulosa y escasas ondulitas.

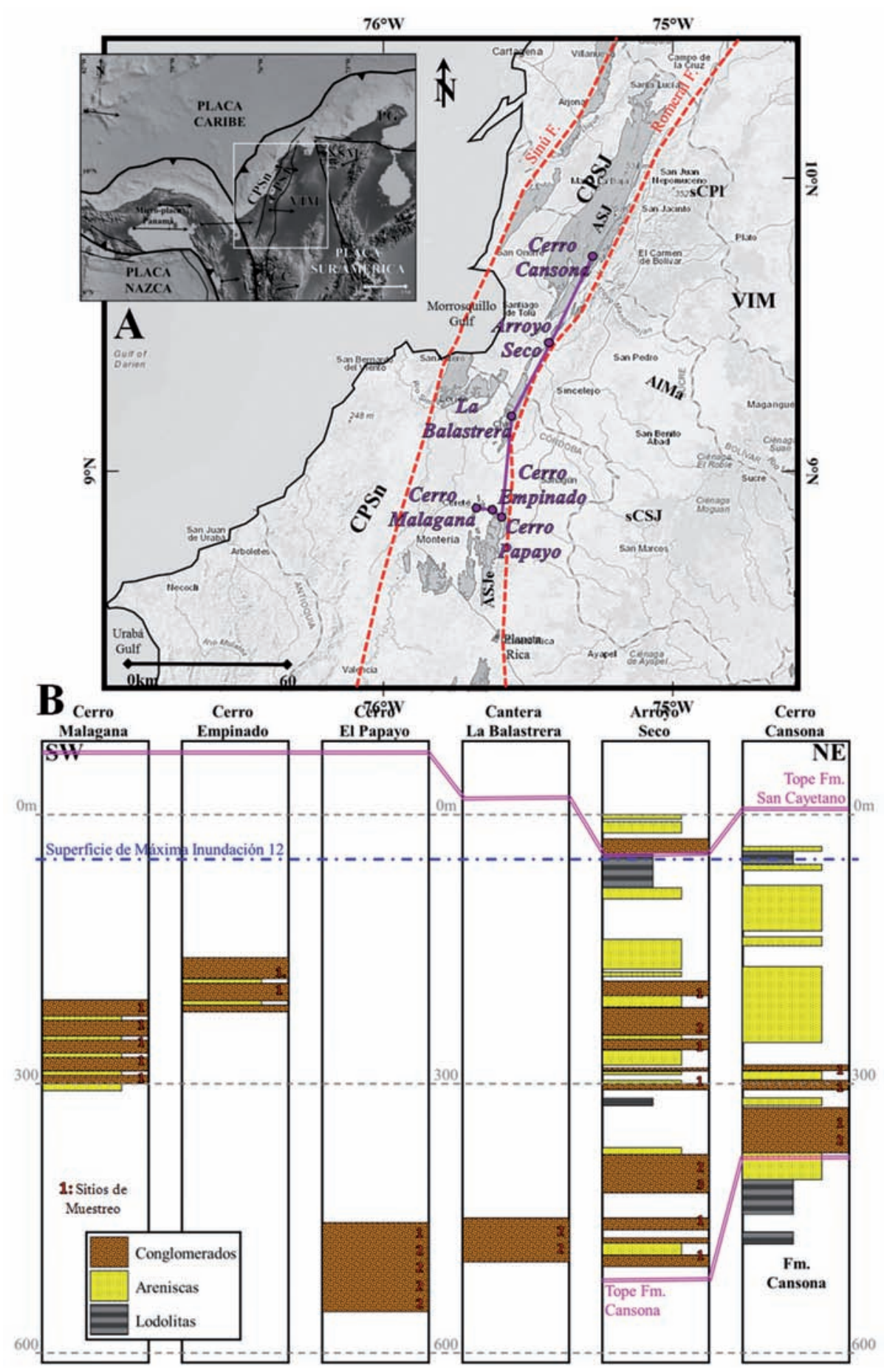

FIGURA 1. A. Localización de los sitios de muestreo de los conglomerados basales de la Formación San Cayetano, afloramientos de las formaciones Cansona y San Cayetano, y principales rasgos tectónicos del área de estudio (CPSn: Cinturón Plegado del Sinú; CPSJ: Cinturón Plegado de San Jacinto; VIM: Valle Inferior del Magdalena; ASJe: Anticlinorio de San Jerónimo; ASJ; Anticlinorio de San Jacinto; sCSJ: Subcuenca de San Jorge; AlMa: Alto de Magangué; sCPl: Subcuenca de Plato). B. Correlación estratigráfica de las seis columnas levantadas: Cerro Cansona, Arroyo Seco, Cantera La Balastrera, y los cerros El Papayo, Empinado y Malagana. 


\section{METODOLOGÍA}

Este estudio incorpora la información obtenida a partir de seis (6) secciones estratigráficas de la Formación San Cayetano, relacionadas en la TABLA 1 y cuya ubicación se indica en la FIGURA 1A. En total se realizaron 37 conteos de clastos, utilizando el método de la cuadrícula y se corrigió el error probable. Posteriormente, se realizó la descripción y clasificación macroscópica de los clastos ígneos, metamórficos y sedimentarios siguiendo las recomendaciones derivadas de las subcomisiones creadas en el marco de la International Union of Geological Sciences, para la sistemática de estas rocas (Le Bas y Streckeisen,
1991; Fettes y Desmons, 2011). La caracterización petrográfica de los clastos en 30 láminas delgadas (TABLA 1), comprendió la identificación mineral, análisis modal (conteo de 150 a 200 puntos por muestra) y descripción microestructural. La clasificación petrográfica se realizó siguiendo la metodología propuesta por: Streckeisen (1976) para las rocas plutónicas; Streckeisen (1979) para las rocas volcánicas. Para la clasificación de los clastos metamórficos, se utilizó la nomenclatura sugerida y compilada en Robertson (1999); mientras que para la clasificación de los clastos sedimentarios, se tomó como referencia la nomenclatura compilada en Hallsworth y Knox (1999).

TABLA 1. Relación de las secciones muestreadas y láminas delgadas analizadas para la Formación San Cayetano en el CPSJ.

\begin{tabular}{|c|c|c|c|c|}
\hline ESTE & NORTE & Sector & Lamina delgada & Tipo de Litología \\
\hline \multirow{8}{*}{870026} & \multirow{8}{*}{1569279} & \multirow{8}{*}{ Cerro Cansona } & $5000140-1$ & Chert \\
\hline & & & $5000141-1$ & Toba cristalo-lítica \\
\hline & & & $5000142-1$ & Granodiorita \\
\hline & & & $5000144-1$ & Toba lítica \\
\hline & & & $5000145-1$ & Basalto amigdaloide \\
\hline & & & $5000148-2$ & Chert \\
\hline & & & $5000149-1$ & Cuarzo-monzodiorita \\
\hline & & & $5000188-1$ & Basalto amigdaloide \\
\hline \multirow{2}{*}{852664} & \multirow{2}{*}{1537107} & \multirow{2}{*}{ Arroyo Seco } & $5000076-1-3-4$ & Granodiorita \\
\hline & & & $5000080-1-3-4$ & Granodiorita \\
\hline \multirow{3}{*}{839776} & \multirow{3}{*}{1509058} & \multirow{3}{*}{$\begin{array}{c}\text { Cantera } \\
\text { La Balastrera }\end{array}$} & $5000088-1-3-4$ & Serpentinita \\
\hline & & & $5000092-1-3-4$ & Andesita \\
\hline & & & $5000093-1-3-4$ & Toba \\
\hline \multirow{13}{*}{835240} & \multirow{13}{*}{1470845} & \multirow{13}{*}{$\begin{array}{c}\text { Cantera } \\
\text { El Papayo }\end{array}$} & $5000162-1$ & Toba cristalo-lítica \\
\hline & & & $5000163-1$ & Toba lítica \\
\hline & & & $5000165-1$ & Basalto amigdaloide \\
\hline & & & $5000165-2$ & Toba lítica \\
\hline & & & $5000167-3$ & Serpentinita \\
\hline & & & $5000169-1$ & Serpentinita \\
\hline & & & $5000171-1$ & Granito \\
\hline & & & $5000172-1$ & Traquita \\
\hline & & & $5000173-1$ & Toba lítica \\
\hline & & & $5000174-2$ & Serpentinita \\
\hline & & & $5000174-3$ & Esquisto anfibolítico \\
\hline & & & $5000175-1$ & Basalto \\
\hline & & & $5000176-1$ & Toba cristalo-lítica \\
\hline \multirow{3}{*}{832117} & \multirow{3}{*}{1472765} & \multirow{3}{*}{ Cerro Empinado } & $5000156-1$ & Basalto amigdaloide \\
\hline & & & $5000156-2$ & Basalto amigdaloide \\
\hline & & & $5000156-3$ & Tobas vitro-cristalinas \\
\hline 823483 & 1474145 & Cerro Malagana & $5000114-1-3-4$ & Dacita \\
\hline
\end{tabular}




\section{RESULTADOS}

A continuación se presentan los resultados del estudio de clastos y el análisis petrográfico en las secuencias conglomeráticas de la Formación San Cayetano en seis (6) sectores del CPSJ (FIGURA 1, TABLA 1) ordenados por familias litologicas. En el área Norte, se muestrearon los sectores de: Cerro Cansona (área de Carmen de Bolívar) donde afloran conglomerados de $\sim 60 \mathrm{~m}$ de espesor (5 conteos); y en Arroyo Seco (área de Toluviejo) afloran $\sim 220 \mathrm{~m}$ de espesor de conglomerados (12 conteos, $\sim 470 \mathrm{~m}$ de espesor total). En el área Centro-Sur, se muestreó el sector de la Cantera La Balastrera (área de Lorica) donde aflora una sección de $\sim 37 \mathrm{~m}$ de espesor de conglomerados (4 conteos). En el área Sur, se muestrearon tres (3) afloramientos de la Formación San Cayetano (área de Ciénaga de Oro) en los sectores de: Cerro El Papayo donde afloran $\sim 100 \mathrm{~m}$ de espesor de conglomerados (9 conteos); Cerro Empinado donde afloran $\sim 57 \mathrm{~m}$ de espesor de conglomerados (2 conteos); y en el Cerro Malagana donde afloran $\sim 100 \mathrm{~m}$ de espesor de conglomerados (5 conteos) (FIGURA 1B).

\section{Clastos ígneos extrusivos}

Los clastos ígneos extrusivos de naturaleza máfica identificados corresponden a basaltos amigdaloides, comunes hacia el Sur en el sector de Cerro El Papayo (láminas 5000165-1 y 5000175-1) y Cerro Empinado (láminas 5000156-2 y 5000156-1); mientras que disminuyen hacia el Norte en los sectores de la Cantera La Balastrera y en el Cerro Cansona (láminas 50001451 y 5000188-1). Generalmente los basaltos descritos se caracterizan por una textura porfídica, localmente con textura glomeroporfídica; están compuestos por fenocristales de: plagioclasa $(25-36 \%)$ con inclusiones de minerales opacos, olivinos ( $8 \%$ ) y piroxenos $(67 \%)$, ambos parcialmente cloritizados; dentro de una matriz (18-30\%) de microcristales de: feldespato, vidrio, óxidos de hierro y clorita; además poseen amígdalas de agregados fibroso-radiales de clorita y zeolita (FIGURA 2A). Algunos basaltos con textura glomeroporfídica localizada presentan alteración de sus fenocristales de plagioclasa $(38 \%)$ y feldespato potásico $(5 \%)$ a sericita y caolinita, respectivamente (lámina 50001881); además la matriz predominantemente vítrea (30\%) presenta una textura fluidal. En el Cerro El Papayo algunos clastos presentan una tonalidad verde claro generada posiblemente por alteración sericítica y localmente propilítica, además de estructuras autobrechificadas que muestra tonalidades ocres a marrónrojizo. El análisis petrográfico de estos clastos (lámina 5000175-1) son clasificados como basaltos de textura porfídica formada por fenocristales aglomerados de plagioclasa (53\%) alterada a sericita (algunas zonadas y con aspecto esquelético), con una matriz que contiene vidrio $(25 \%)$, clorita $(1 \%)$, microcristales de plagioclasa (15\%) y feldespato alcalino (5\%); ocasionalmente presenta fenocristales de piroxenos (1\%) fuertemente alterados a clorita y con bordes de oxidación (FIGURA 2B).

Las andesitas se identifican macroscópicamente hacia la zona Sur en el sector de Cerro Empinado (32\%) y disminuyen hacia la zona Central-Sur en la Cantera La Balastrera (10\%) y en el Cerro Malagana (17\%). Los clastos de andesita (6 a $8 \mathrm{~cm}$ de diámetro) presentan fenocristales de plagioclasa ( $3 \mathrm{~mm}$ de espesor) y anfíbol, en una matriz afanítica. La andesita de la Cantera La Balastrera (lámina 5000092-1-3-4) posee una textura porfídica que contiene fenocristales alineados de plagioclasa $(40 \%)$ alterada a sericita y calcita; hornblenda (30\%) alterada a clorita, y óxidos de hierro (magnetita); la matriz se compone de microcristales de cuarzo $(15 \%)$, plagioclasa $(8 \%)$, feldespato alcalino $(2 \%)$ y hornblenda $(5 \%)$ con alteraciones de calcita y clorita.

También se identificaron clastos de dacitas en los afloramientos del sector del Cerro Cansona (34\%) en donde aparecen en clastos de $\sim 10 \mathrm{~cm}$ de diámetro, de color gris oscuro; y hacia el Sur, en el sector del Cerro Malagana donde son mucho más escasas. En el Cerro Malagana se describen petrográficamente como Dacita porfídica (lámina 5000114-1-3-4) compuesta de fenocristales de plagioclasa $(30 \%)$, cuarzo con embahiamientos (5\%), feldespato alcalino (5\%) y biotita $(10 \%)$ alterada a clorita y óxidos de hierro (magnetita), dentro de una matriz microcristalina (50\%) de la misma composición. Hacia el Sur, en el Cerro El Papayo se identificó petrográficamente una Traquita (lámina 5000172-1) compuesta de microcristales de feldespato alcalino y plagioclasa, alineados en dirección del flujo, además de bandas milimétricas de clorita que cortan la roca (FIGURA 2C).

\section{Clastos ígneos piroclásticos}

Los clastos piroclásticos identificados son tobas que se concentran hacia el Sur, en los sectores de los cerros El Papayo y Empinado; y disminuyen hacia el Norte en el sector de Cerro Cansona y Arroyo Seco. Petrográficamente en el sector de Cerro El Papayo se identificaron: tobas cristalo-líticas conformadas por cristales de plagioclasa (40-32\%), clinopiroxenos (25$15 \%)$, hornblenda $(0-20 \%)$, y feldespato alcalino (5-3\%) (láminas 5000176-1 y 5000162-1, respectivamente); una de las tobas posee fragmentos tamaño ceniza gruesa $(5 \%)$ de basalto en textura porfídica algunos muy cloritizados, y una matriz (35\%) compuesta de: 
clorita, esmectita-montmorillonita y vidrio (FIGURA 2D); mientras que la otra toba posee fragmentos (20\%) tamaño lapilli y ceniza gruesa de andesitas y basaltos en textura porfídica y una matriz microcristalina $(10 \%)$ compuesta de cuarzo, vidrio, feldespatos, anfíboles y piroxenos (FIGURA 2E).

También se identificaron petrográficamente tobas líticas, algunas compuestas de fragmentos tamaño lapilli de cuarcitas (65\%), esquistos cuarzo-micáceos $(5 \%)$ dacitas $(10 \%)$ de textura porfídica, y en menor proporción cristales de: cuarzo (8\%), plagioclasa (4\%) y minerales opacos $(3 \%)$, en una matriz compuesta por vidrio alterado a palagonita $(4 \%)$, calcita $(<1 \%)$ y clorita (1\%) (lámina 5000163-1); o, compuestas de fragmentos tamaño lapilli y ceniza gruesa de cuarzo policristalino
$(25 \%)$, chert $(5 \%)$, dacitas de textura porfídica $(2 \%)$, andesitas $(1 \%)$, cuarcita $(10 \%)$, esquistos cuarzomicáceos $(5 \%)$ y plutónicos de composición intermedia (Tr), en menor proporción cristales de: cuarzo (15\%), plagioclasa $(5 \%)$, piroxenos $(2 \%)$, hornblenda $(\mathrm{Tr}) \mathrm{y}$ minerales opacos (Tr), en una matriz microcristalina (30\%) compuesta de: cuarzo, plagioclasa, feldespato alcalino, piroxenos, clorita y esmectita-montmorillonita (lámina 5000165-2); y finalmente, compuestas de fragmentos de tamaño ceniza gruesa y lapilli de andesitas y basaltos en textura porfídica y amigdaloide $(25 \%)$, dacitas $(5 \%)$, cuarcita $(5 \%)$, esquisto cuarzomicáceos $(3 \%)$ e intrusivos de composición félsica $(1 \%)$, cristales de cuarzo (8\%), plagioclasa $(10 \%)$, clino y ortopiroxenos $(23 \%)$, en una matriz $(20 \%)$ de clorita, vidrio y esmectita-montmorillonita (FIGURA 2F).
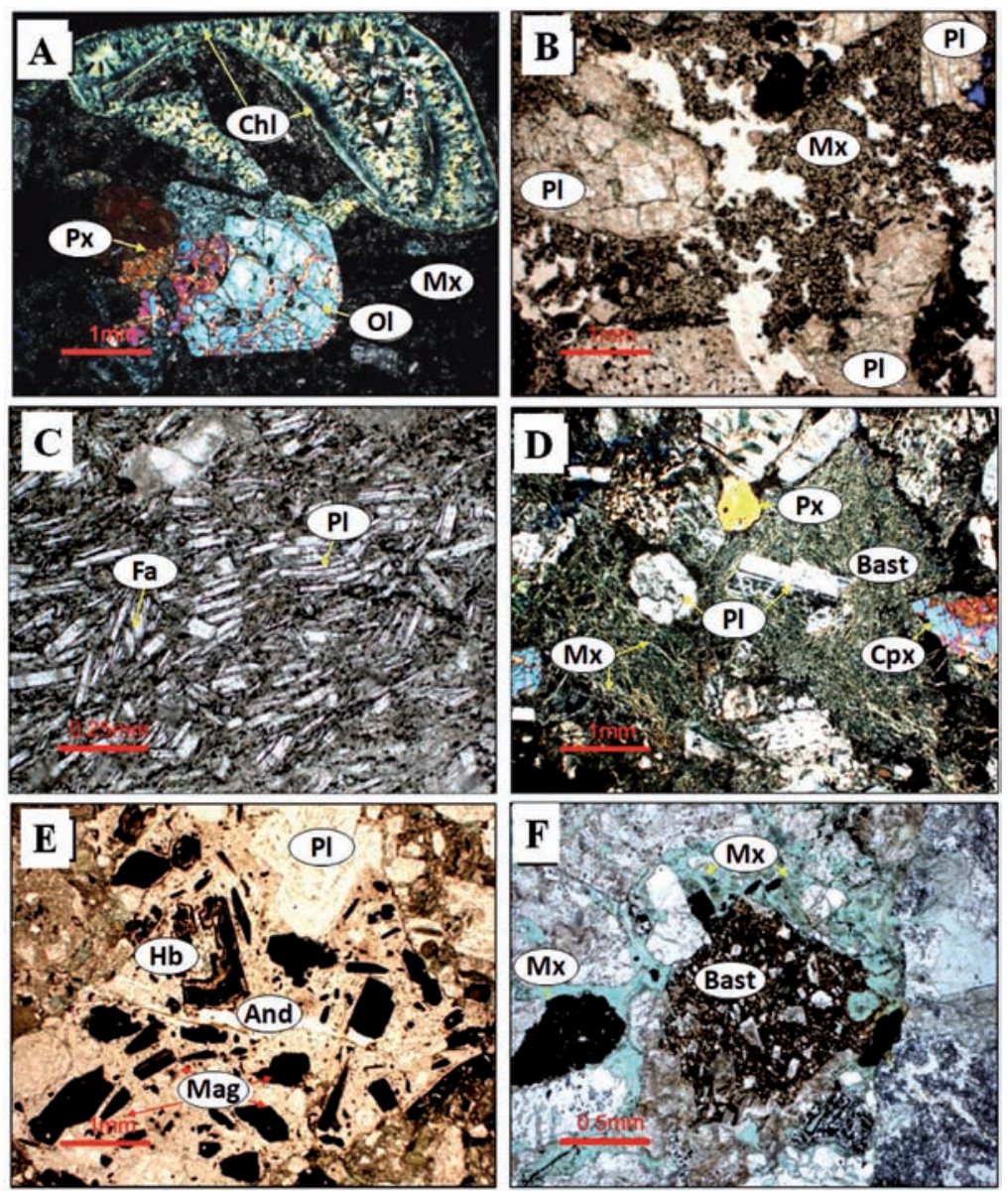

FIGURA 2. A. Basalto (muestra 5000165-1) con fenocritales de piroxenos (Px) y olivino (Ol) y amígdalas rellenas de clorita (Chl) en textura fibroso-radial, dentro de una matriz $(\mathrm{Mx})$ microcristalina de color oscuro compuesta de feldespatos, vidrio, óxidos de hierro y clorita (NC-2.5X). B. Basalto (muestra 5000175-1) con fenocristales aglomerados de plagioclasa (Pl) alterada a sericita, embebidos en una matriz (Mx) de vidrio, feldespatos y clorita (NP-2,5X). C. Traquita (muestra 5000172-1) con microcristales de feldespato alcalino $(\mathrm{Fa})$ y plagioclasa $(\mathrm{Pl})$ alineados en dirección del flujo (NP-2.5X). D. Toba cristalo-lítica (muestra 50001761) con cristales de plagioclasas $(\mathrm{Pl})$, clinopiroxenos $(\mathrm{Cpx})$ y fragmentos líticos de basaltos (Bast), en una matriz ( $\mathrm{Mx})$ de clorita, esmectita-montmorillonita y vidrio (NX-2,5X). E. Toba cristalo-lítica (muestra 5000162-1) con fragmentos líticos de andesita (And) que contiene fenocristales de plagioclasa $(\mathrm{Pl})$ y hornblenda $(\mathrm{Hb})$ con óxidos de hierro (magnetita, Mag) (NP-2,5X). F. Toba lítica (muestra 5000173-1) con fragmentos de andesita y basaltos (Bast), en una matriz (Mx) de clorita, vidrio y esmectitamontmorillonita (NP-5X). 
En el sector de la Cantera La Balastrera (lámina 5000931-3-4) se describe una toba compuesta de fragmentos cristalinos de cuarzo, plagioclasa y micas, dentro de una matriz que contiene vidrio, minerales arcillosos y calcita. En el extremo Norte del área de estudio en el Cerro Cansona se describen petrográficamente una toba cristalina (lámina 5000141-1) con cristales de feldespato alcalino (30\%), plagioclasa $(15 \%)$, cuarzo $(20 \%)$, hornblenda $(<1 \%)$; y fragmentos líticos (5\%) tamaño ceniza gruesa de andesitas y basaltos de textura porfídica y amigdaloide, en una matriz microcristalina que en algunas partes tiene un aspecto fluidal compuesta de microcristales de cuarzo (10\%), vidrio $(5 \%)$, esmectita-montmorillonita $(10 \%)$, calcita en parches $(2 \%)$ y minerales opacos $(3 \%)$; además de, una toba lítica (lámina 5000144-1) compuesta de fragmentos tamaño ceniza y lapilli de basaltos y andesitas porfídicas y amigdaloides (53\%), algunos de estos líticos se componen de vidrio y esferulitas de clorita (5\%); cristales de plagioclasa (20\%), feldespato potásico $(5 \%)$ y piroxenos (clino y orto) alterados parcialmente a clorita $(7 \%)$, dentro de una matriz $(10 \%)$ que contiene vidrio alterado a palagonita, clorita, calcita y microcristales de feldespatos, cuarzo y piroxenos.

\section{Clastos ígneos intrusivos}

Los clastos ígneos intrusivos de naturaleza ultramáfica identificados corresponden con los clastos de peridotitas serpentinizadas presentes al Sur del área, aunque por su descripción petrográfica se clasifican como serpentinitas y por lo tanto son descritos en el apartado de clastos metamórficos. Dentro de los clastos de naturaleza máfica se identificaron gabros al Sur del área de estudio, en los sectores de la cantera La Balastrera (16\%) y los cerros de El Papayo (7\%) y Malagana (5\%). En el sector de La Balastrera los gabros se encuentran en clastos de $10-15 \mathrm{~cm}$ de diámetro, compuestos por: piroxeno (66\%) (2-15 $\mathrm{mm}$ de diámetro) en masas monominerales elongadas $(10 \mathrm{~cm}$ de longitud y $1,5 \mathrm{~cm}$ de espesor) y plagioclasas (23\%).

Los clastos ígneos intrusivos de naturaleza intermedia como las dioritas son identificados hacia el Norte en el sector de Cerro Cansona (5\%) donde aparecen clastos de $\sim 10 \mathrm{~cm}$ de diámetro, con textura fanerítica panidiomorfa de grano grueso $(>2 \mathrm{~mm})$, compuestos por: plagioclasa, anfíbol (3-5 $\mathrm{mm}$ de longitud), cuarzo y en algunas ocasiones biotita alargada $(\sim 1 \mathrm{~cm}$ de longitud y $\sim 1 \mathrm{~mm}$ de espesor). Mientras que en el sector de Arroyo Seco (1\%), los clastos de $\sim 3 \mathrm{~cm}$ de diámetro presentan sericitización (coloración verde clara) de la plagioclasa (de 2-3 mm) y magnetita como mineral accesorio. El análisis petrográfico de uno de estos clastos de Cerro Cansona hizo posible su clasificación como: cuarzo-monzodiorita (lámina 5000149-1) con textura hipidiomórfica inequigranular compuesta de cristales de plagioclasa $(60 \%)$, feldespato alcalino $(9 \%)$, cuarzo $(15 \%)$, biotita $(10 \%)$, hornblenda $(1 \%)$ y piroxenos $(5 \%)$ alterados a clorita.

También se identificaron clastos de granodioritas que varían en tamaño de 10 a $15 \mathrm{~cm}$ de diámetro y se identifican tanto en la zona Norte, en los sectores de Cerro Cansona (10\%) y Arroyo Seco (3\%), como en la zona Sur en el Cerro El Papayo (19\%). El análisis petrográfico de la granodiorita del Cerro Cansona (lámina 5000142-1) muestra una textura hipidiomórfica inequigranular compuesta de cristales subhedrales y euhedrales de plagioclasa (45\%) alterada a sericita y epidota, cuarzo (35\%), feldespato potásico $(10 \%)$ y biotita $(10 \%)$ fuertemente alterada a clorita y ocasionalmente con deformación intracristalina. En el sector de Arroyo Seco, las granodioritas (láminas 5000076-1-3-4 y 5000080-1-3-4) presentan texturas holocristalina y poiquilítica inequigranular, compuesta por cristales euheudrales o subheudrales de plagioclasa (51\%) alterada a epidota y clorita, hornblenda (22\%) con inclusiones de magnetita, feldespato potásico $(15,2 \%)$ ocasionalmente con texturas pertíticas, y biotita (7\%).

Los clastos ígneos intrusivos de naturaleza félsica están representados por granitoides que fueron identificados al Norte en el sector de Arroyo Seco (6\%), donde aparece en bloques $(<1 \mathrm{~m}$ de diámetro) que presentan una orientación preferente de la biotita y de los anfíboles; además de, algunos clastos de pegmatitas $(<1 \%) \quad(\sim 3 \mathrm{~cm}$ de diámetro). Mientras que hacia el Sur, en los cerros Empinado (5\%) y Malagana (5\%) el tamaño de los clastos disminuye considerablemente presentándose clastos de $3-8 \mathrm{~cm}$ de diámetro, con textura equigranular.

\section{Clastos sedimentarios}

En la zona Norte los clastos de origen sedimentario comprenden el 14\% de los clastos encontrados en el Cerro Cansona y aumentan al $24 \%$ en Arroyo Seco (TABLA 2); en ambos sectores predominan los clastos de chert negro, en el Cerro Cansona aparecen clastos de areniscas de grano grueso $(<2 \%)$ con líticos de morfologías irregulares y microfracturas rellenas de calcita (también en el chert). Mientras que en Arroyo Seco, aparecen intercalaciones chert negro-arenisca fina 
(2-4 cm de diámetro); areniscas finas a muy finas, líticas, con cemento calcáreo ( $\sim 3 \mathrm{~cm}$ de diámetro); limolitas calcáreas de $\sim 3 \mathrm{~cm}$ de diámetro y calizas (mudstones) ( $\sim 3 \mathrm{~cm}$ de diámetro) de color gris oscuro, localmente con vetillas de cuarzo ( $2 \mathrm{~mm}$ de espesor).

En la zona Centro-Sur (Cantera La Balastrera y Cerro El Papayo) los clastos de origen sedimentario componen el $16 \%$ de los clastos identificados y se componen principalmente por chert negro de 3-5 $\mathrm{cm}$ de diámetro (Cantera La Balastrera: 7\%, y Cerro El Papayo: 10\%); y calizas micriticas (mudstones) de 8-10cm de diámetro (Cantera La Balastrera: 9\%, y Cerro El Papayo: 6\%) de color gris oscuro, algunas de los cuales presentan aspecto brechoide (sin-depositacionales).

En la zona Sur los clastos de origen sedimentario comprenden el 35\% de los clastos identificados en el Cerro Empinado y disminuyen al 19\% en el Cerro Malagana; los clastos en el Cerro Empinado se componen por: chert negro e intercalaciones de chert negro-arenisca fina $(25 \%)$ (1-3 $\mathrm{cm}$ de diámetro); calizas micríticas a ligeramente esparíticas y margas (10\%) ( 20-40 cm de diámetro). Los clastos de Cerro Malagana se componen por: areniscas de grano grueso, líticas y cemento calcáreo (14\%) ( 4 cm de diámetro); además de calizas y margas $(5 \%)$.

TABLA 2. Distribución de las variedades litológicas de clastos (\%) en los conglomerados de la Formación San Cayetano (CPSJ).

\begin{tabular}{|c|c|c|c|c|c|c|}
\hline $\begin{array}{l}\text { Litología de los Clastos (\%) } \\
\text { en Afloramientos }\end{array}$ & $\begin{array}{l}\text { 1. Cerro } \\
\text { Cansona }\end{array}$ & $\begin{array}{l}\text { 2. Arroyo } \\
\text { Seco }\end{array}$ & $\begin{array}{l}\text { 3. Cantera La } \\
\text { Balastrera }\end{array}$ & $\begin{array}{l}\text { 4. Cerro El } \\
\text { Papayo }\end{array}$ & $\begin{array}{l}\text { 5. Cerro } \\
\text { Empinado }\end{array}$ & $\begin{array}{l}\text { 6. Cerro } \\
\text { Malagana }\end{array}$ \\
\hline Ígneo intrusivo & 15 & 9 & 21 & 34 & 5 & 10 \\
\hline Ígneo extrusivo & 45 & 37 & 57 & 36 & 40 & 61 \\
\hline Piroclástico & 8 & 8 & 2 & 10 & 10 & \\
\hline TOTAL ROCAS IGNEAS & 68 & 54 & 80 & 80 & 55 & 71 \\
\hline $\begin{array}{l}\text { TOTAL ROCAS } \\
\text { SEDIMENTARIAS }\end{array}$ & 14 & 24 & 16 & 16 & 35 & 19 \\
\hline $\begin{array}{l}\text { TOTAL ROCAS } \\
\text { METAMORFICAS }\end{array}$ & 2 & 5 & 2 & 2 & 5 & 5 \\
\hline Cuarzo segregado & 16 & 17 & 2 & 2 & 5 & 5 \\
\hline
\end{tabular}

\section{Clastos metamórficos}

En la zona Norte los clastos de origen metamórfico comprenden el $2 \%$ de los clastos identificados en el Cerro Cansona y aumentan al 5\% en el sector de Arroyo Seco (TABLA 2); los clastos metamórficos en el Cerro Cansona se componen por: filitas $(\sim 7$ $\mathrm{cm}$ de diámetro) con textura granolepidoblástica, algunos con alteraciones supergénicas de jaroisita y caolinita; filitas con cuarzos 'boudinados' $(\sim 1 \mathrm{~cm}$ de longitud $\mathrm{y} \sim 1 \mathrm{~mm}$ de espesor); y filitas (meta-areniscas de grano fino-muy fino) con zonas de enrejado (tipo stockwork, vetillas de 1-2 mm de espesor), compuesto por cuarzo \pm dolomita. Mientras que los clastos en el sector de Arroyo Seco están compuestos por: pizarras de cuarzo y sericita (clorita?) ( $\sim 5 \mathrm{~cm}$ de diámetro), con textura lepidoblástica y estrías en algunas superficies de exfoliación; mármol, y cuarcitas ( $<3 \mathrm{~cm}$ de diámetro), localmente con zonas enrejadas.
En la zona Centro-Sur (Cantera La Balastrera y Cerro El Papayo) los clastos de origen metamórfico componen el $2 \%$ de los clastos identificados y se identifican en ambos sectores filitas (3-6 cm de diámetro) de cuarzo y sericita (clorita?) con textura lepidoblástica; anfibolitas (3-6 cm de diámetro) con textura nematoblástica en la Cantera La Balastrera; y esquistos anfibolíticos epidotizados (protolito máfico) con textura nematoblástica en el Cerro El Papayo.

En la zona Centro-Sur aparecen clastos de peridotitas serpentinizadas (Cantera La Balastrera: 5\%, y Cerro El Papayo: 8\%) (8-10 cm de diámetro) de color negro con pátinas verdes a verde claro en su totalidad dependiendo del grado de alteración de las rocas ultramáficas (tipo serpentina-talco-clorita), además de una textura enrejada en la superficie de los clastos. Petrograficamente se describió uno de los clastos del sector de La Balastrera como serpentinita (lámina 
5000088-1-3-4), la cual posee minerales derivados de la alteración de rocas ultramáficas, como: lizardita con textura en mallas asociada con olivino, magnetita, clorita y talco (FIGURA 3A); serpentina formando pseudomorfos (bastitas) reemplazando orto-piroxenos y clino-piroxenos. En el sector del Cerro El Papayo se describieron petrográficamente tres (3) muestras de serpentinitas (láminas 5000167-3, 5000169-1 y 5000174-2) que están compuestas de minerales del grupo de la serpentina como lizardita y antigorita que están alterando fuertemente los piroxenos y olivinos, que aparecen como relictos generando una textura pseudomórfica (FIGURA 3B y 3C). Como accesorios se encuentran magnetita y cromo-espinela en cristales fracturados; y ocasionalmente se identifican procesos de carbonatación por la presencia de calcita en agregados cristalinos (FIGURA 3D).
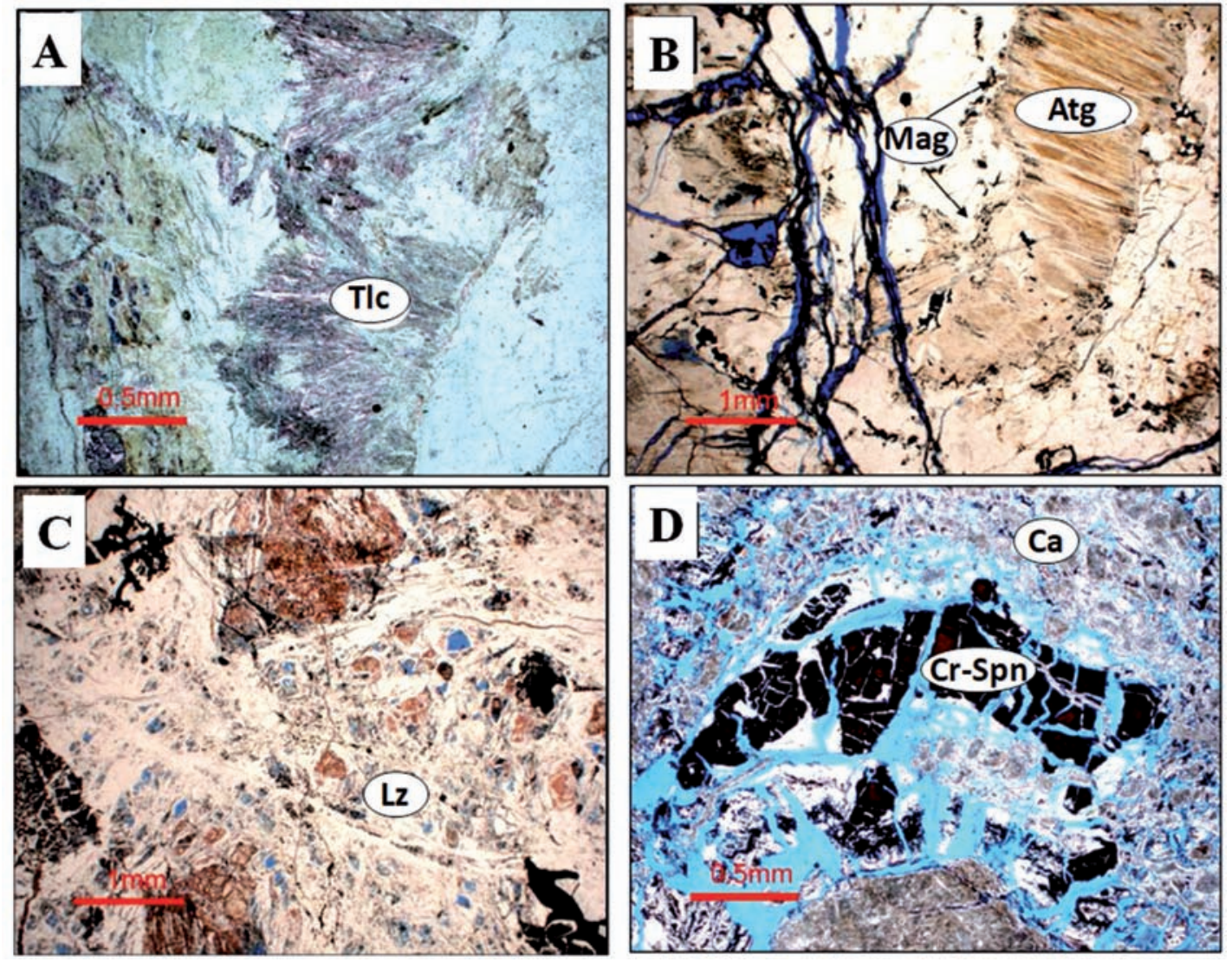

FIGURA 3. Petrografía de las muestras de serpentinitas de la Cantera La Balastrera (A) y de Cerro El Papayo (B, C y D). A. Serpentinita (5000088-1-3-4) con alteraciones locales a talco (Tlc) (NP-5X). B. Agregados anhedrales de Antigorita (Atg) y magnetita (Mag) en serpentinita (5000169-1) (NP-2.5X). C. Serpentinita (muestra 5000167-3) con lizardita (Lz) caracterizada por su estructura típica en malla (NP-2,5X). D. Serpentinita (5000174-2) con calcita (Ca) y minerales opacos como cromoespinela (Cr-Spn) en cristales fracturados (NP-5X).

En la zona Sur (Cerro Empinado y Cerro Malagana) los clastos de origen metamórfico componen el 5\% de los clastos identificados en el sector de Cerro Empinado: filitas silíceas y filitas cuarzo-sericíticas (ligeramente grafíticas) $(3-4 \mathrm{~cm}$ de diámetro) con textura lepidoblástica. Mientras que en el sector del Cerro Malagana, se identifican clastos de: ortogneis (8-15 cm de diámetro) de textura grano-nematoblástica y puntualmente grano-porfidoblástica, que se compone de plagioclasa, anfíbol, feldespato potásico y cuarzo; además de esquistos cuarzo-micáceos ( $\sim 6$ $\mathrm{cm}$ de diámetro) de color gris oscuro, con textura granolepidoblástica.

En la zona Norte (Cerro Cansona y Arroyo Seco) aparecen clastos de cuarzo cristalino lechoso (de 2-3 $\mathrm{cm}$ de diámetro), en una proporción de 16 a $18 \%$ (respectivamente), que disminuye al 2\% de los clastos 
identificados en la zona Centro-Sur (Cantera La Balastrera y Cerro El Papayo), y aumenta su presencia al $5 \%$ en los clastos identificados en la zona Sur (Cerro Empinado y Cerro Malagana) (TABLA 2). En el sector del Cerro Malagana, algunos de los clastos de cuarzo contienen fragmentos de rocas metamórficos en su interior; además de la presencia de cuarzo y moscovita en venas $(0,5-1,0 \mathrm{~cm}$ de espesor) producto de la segregación metamórfica, en esquistos cuarzomicáceos.

\section{DISCUSIÓN}

De acuerdo con la cuantificación y descripción macroscópica de clastos, y los análisis petrográficos microscópicos en los seis (6) afloramientos de conglomerados basales de la Formación San Cayetano; el área de estudio se puede dividir en dos (2) sectores: Norte (Cerro Cansona y Arroyo Seco) y Sur (Cantera La Balastrera y, Cerros El Papayo, Empinado y Malagana). En el sector Norte abundan los clastos ígneos extrusivos de afinidad intermedia y máfica (basaltos con vacuolas, andesita y dacita), y algunos clastos ígneos intrusivos, donde predominan los de afinidad intermedia (dioritas y granodioritas) y solo de afinidad félsica (granitoides y pegmatitas) en Arroyo Seco. En el sector Sur predominan los clastos ígneos extrusivos de afinidad máfica e intermedia (basaltos con vacuolas, andesitadacita y algunos basaltos sin vacuolas), además de clastos ígneos intrusivos de afinidad ultramáfica y máfica (peridotitas serpentinizadas y gabros) y escasos de afinidad félsica (granitoides) solo en los cerros Empinado y Malagana (FIGURA 4). La separación entre los dos sectores corresponde con el área de Sincelejo (entre Arroyo Seco y la Cantera La Balastrera) y está marcada por la presencia hacia el Sur de clastos de afinidad ultramáfica y máfica como serpentinitas, gabros y basaltos sin vacuolas, los cuales no son reportados en las mismas secuencias conglomeráticas hacia el Norte. La presencia de clastos de basalto con vacuolas evidencian la inmiscibilidad o separación de una fase vapor, por procesos de despresurización del magma silicatado (Best y Christiansen, 2001); este tipo de basalto con vacuolas también ha sido reportado en el basamento del pozo Apure-1 en la Subcuenca de Plato (sCPl), en donde las anomalías magnéticas identificadas en la subcuenca corresponden con basaltos y andesitas (pozos Apure-1, Apure-2 y Remolino-1) y cuyo análisis geoquímico correlaciona dicha litología con un ambiente de arco magmático en un corteza continental adelgazada (Silva-Arias et al., 2016).

La composición de los clastos identificados en los conglomerados basales en las seis (6) secciones de la Fm San Cayetano al Sur del CPSJ, muestran una relación tectónica con un ambiente que varía entre un 'Arco No Disectado a Disectado' (Dickinson y Suczek, 1979; y Dickinson et al., 1983). Su correlación con un ambiente tectónico de 'Arco No Disectado' está asociado a la presencia de rocas volcánicas intermedias a máficas, intrusivas máficas y ultramáficas, y líticos (metamórficos y sedimentarios) como se aprecia hacia el sector Sur; mientras que la influencia hacia un 'Arco Disectado' está marcada por la inclusión de rocas intrusivas (más félsicas) y meta-ígneas, como se observa en el Norte del área (FIGURA 4).

La distribución de los clastos hacia los dos sectores durante el Paleógeno Temprano, pudo haber sido influenciada por áreas fuentes como el Alto de Magangué (AlMa) que pudo aportar clastos ígneos extrusivos-intrusivos intermedios-máficos del Arco magmático de Magangué (Silva-Arias et al., 2016) hacia toda el área, y que a la vez hizo de barrera para la distribución de sedimentos desde el VIM (sCPl) hacia el área Sur; y como segunda área fuente, se proponen escamas exhumadas de las Peridotitas de Planeta Rica que aportan clastos ígneos extrusivos-intrusivos ultramáficos-máficos de afinidad más oceánica, solo hacia el área Sur (FIGURA 4). En cuanto a los clastos de origen metamórfico estos también presentan una distribución diferencial, los clastos de la zona Norte se consideran más afines con el basamento metamórfico del VMM; mientras que los clastos de la zona Sur se consideran más afines a un protolito ultramáfico-máfico (serpentinitas, ortogneis y anfibolitas). Los clastos sedimentarios se consideran de áreas de la cuenca donde se desmantelaron materiales de la misma Formación Cansona (Duque-Caro, 1973; GEOTEC, 1997; 2003; Guzmán et al., 2004; Guzmán, 2007). La ubicación de las áreas fuente con respecto a las zonas de depositación durante el Paleógeno Temprano parece presentar una configuración muy similar a la configuración actual; en especial si todos los escenarios tectónicos identificados para los conglomerados de la Formación San Cayetano están relacionados con un mínimo a moderado efecto del clima, rápida erosión, y un mínimo efecto del transporte (Dickinson y Suczek, 1979) (FIGURA 4). 


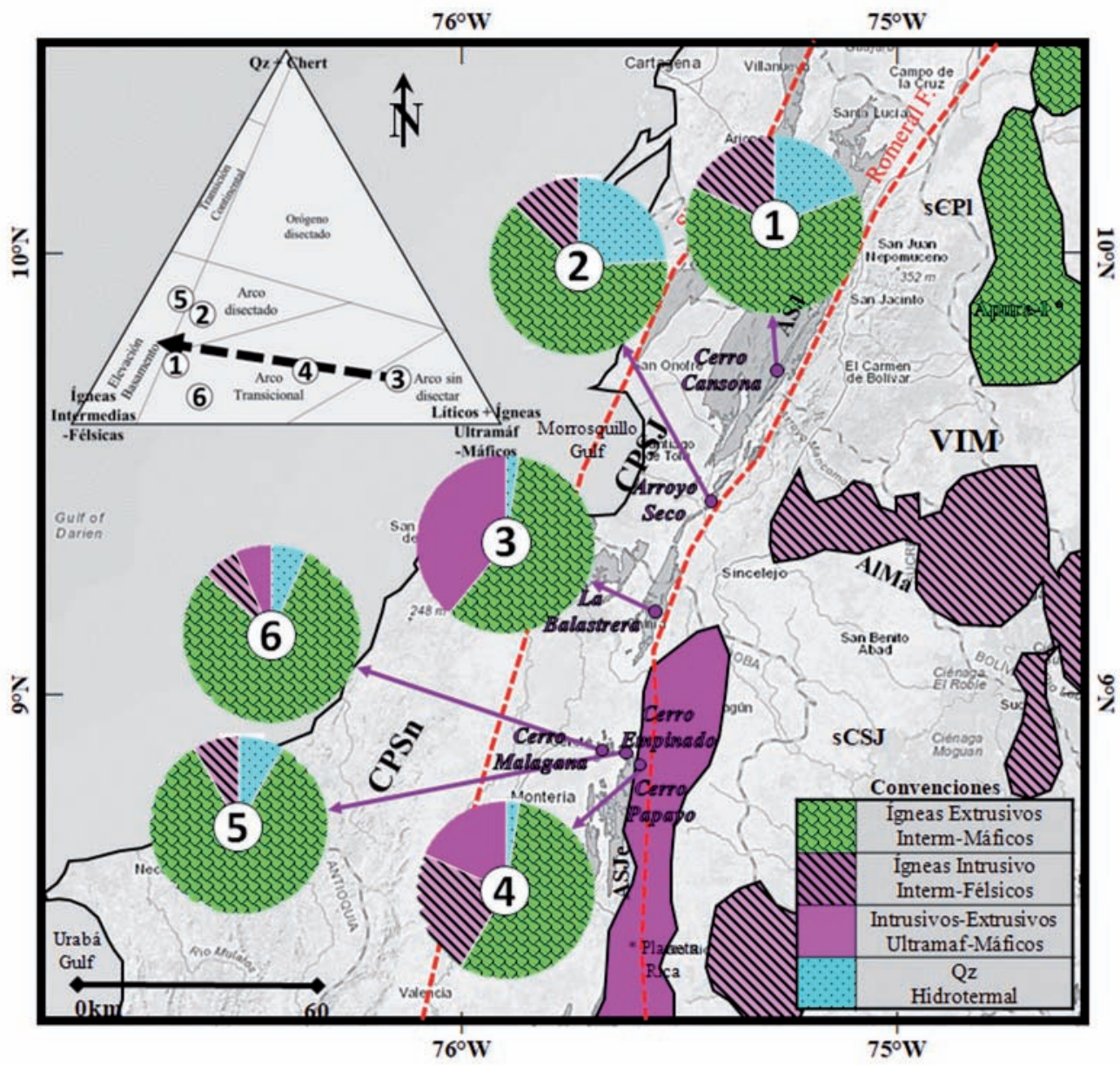

FIGURA 4. Diagramas de distribución de clastos de la Formación San Cayetano (TABLA 2) vs posibles áreas fuente: Peridotitas de Planeta Rica y Alto de Magangué en el basamento del VIM (modificado de Silva-Arias et al., 2016); y relación de la composición de los conglomerados y el ambiente tectónico (modificado de Dickinson y Suczek, 1979).

\section{CONCLUSIONES}

Los clastos de los niveles conglomeráticos basales de la Formación San Cayetano al Sur entre Cantera La Balastrera y los cerros El Papayo, Empinado y Malagana, se diferencian (frente al AlMa) por la presencia exclusiva de clastos de afinidad máfica (basaltos con y sin vacuolas, y gabros) y clastos de origen metamórfico (serpentinitas, ortogneis y anfibolitas), los cuales presentan afinidad con un protolito ultramáfico-máfico que no se encuentran en los niveles conglomeráticos al Norte entre Cerro Cansona y Arroyo Seco.

Los clastos identificados en los conglomerados basales de la Formación San Cayetano (entre las poblaciones de Carmen de Bolívar y Ciénaga de Oro) están relacionados tectónicamente con un ambiente de Arco que de acuerdo con la composición de los clastos se puede clasificar como No Disectado a Disectado, lo que evidencia un mínimo a moderado efecto del clima, rápida erosión, y un mínimo efecto del transporte, por lo cual se sugieren fuentes muy cercanas a la depositación de los clastos.

La distribución de los clastos en las dos áreas de conglomerados de la Formación San Cayetano pudo haber estado influenciada durante el Paleógeno Temprano por el AlMa que aportó clastos del Arco magmático del Magangué desde el VIM y por escamas exhumadas de las Peridotitas de Planeta Rica que aportó los clastos de afinidad ultramáfica y máfica al Sur del CPSJ. La ubicación de las áreas fuente con respecto a las zonas de depositación durante el Paleógeno Temprano parece presentar una configuración muy similar a la configuración actual. 


\section{AGRADECIMIENTOS}

Esta investigación fue financiada por el Instituto Colombiano del Petróleo, ICP-ECOPETROL S.A en el marco del proyecto 'Estudio de rocas pre-Neógenas en el Caribe Colombiano a través de cronoestratigrafía, geoquímica, análisis de proveniencia y termocronología'. Agradecemos a los profesionales que con sus observaciones de campo, recolección de datos, y discusiones técnicas enriquecieron esta investigación. También agradecemos a los revisores anónimos por sus comentarios y sugerencias que nos permitieron mejorar y aclarar el manuscrito.

\section{REFERENCIAS}

Alfonso, M., Herrera, J.M, Navarrete, R.E, Bermúdez, H.D., Calderón, J.E., Parra, F.E., Sarmiento, G., Vega, F., y Perrilliat, M. (2009). Cartografía geológica, levantamiento de columnas estratigráficas, toma de muestras y análisis bioestratigrágicos. Sector Chalán. Bogotá. Informe Geológico. Agencia Nacional de Hidrocarburos-ATG.

Barrero, D., Pardo, A., Vargas C.A., and Martínez, J. (2007). Colombian sedimentary basins: nomenclature, boundaries and petroleum geology, a New Proposal (1ra Ed.). Agencia Nacional de Hidrocarburos. Bogotá, Colombia.

Bermúdez, H., Grajales, J., Restrepo, L., y Rosero, J. (2009). Estudio Integrado de los núcleos y registros obtenidos de los pozos someros tipo "slim holes" en la Cuenca del Sinú. Tomo 1, Anexo 1. Bogotá. Agencia Nacional de Hidrocarburos Universidad de Caldas.

Best, M.G., and Christiansen, E.H. (2001). Igneous Petrology. Oxford: Blackwell Science.

Cardona, A., Valencia, V., Garzón, A., Montes, C., Ojeda, G., Ruiz, J., and Weber, M. (2010). Permian to Triassic I to S-type magmatic switch in the northeast Sierra Nevada de Santa Marta and adjacent regions, Colombian Caribbean: tectonic setting and implications within Pangea paleogeography. Journal of South American Earth Sciences, 29(4), 772-783. doi: 10.1016/j. jsames.2009.12.005.
Cardona, A., Montes, C., Ayala, C., Bustamante, C., Hoyos, N., Montenegro, O., Ojeda, C., Niño, H., Ramírez, V., Valencia, V., Rincón, D., Vervoot, J., and Zapata, S. (2012). From arc-continent collision to continuous convergence, clues from Paleogene conglomerates along the southern CaribbeanSouth America plate boundary. Tectonophysics, 580, 58-87. doi: 10.1016/j.tecto.2012.08.039.

Cediel, J.F., Shaw, R.P., and Cáceres, C. (2003). Tectonic assembly of the Northern Andean Block. In: C. Bartolini, R.T. Buffler, J. Blickwede (Eds.). The Circum-Gulf of Mexico and the Caribbean: Hydrocarbon habitats, basin formation, and plate tectonics (pp. 815-848). AAPG Memoir, 79.

Cerón, J.F., Kellogg, J., and Ojeda G. (2007). Basement configuration of the northwestern South AmericaCaribbean margin from recent geophysical data. CT\&F - Ciencia, Tecnología y Futuro, 3(3), 2549.

Dickinson, W.R., and Suczek, C. (1979). Plate tectonics and sandstone composition. AAPG Bulletin, 63(12), 2164-2182. doi: 10.1306/2F9188FB16CE-11D7-8645000102C1865D.

Dickinson, W.R., Beard, L.S., Brakenridge, G.R., Erjavec, J.L., Ferguson, R.C., Inman, K.F., Knepp, R.A., Lindberg, F.A., and Ryberg, P.T. (1983). Provenance of North American Phanerozoic sandstones in relation to tectonic setting. GSA Bulletin, 94(2), 222-235. doi: 10.1130/0016-7606(1983)94<222:PONAPS $>2.0$ .CO;2

Duque-Caro, H. (1973). The geology of the Monteria area: Colombian Society of Petroleum Geologist and Geophysics. 14th Annual Field Conference. Bogotá, Colombia.

Duque-Caro, H., Guzman, G., y Hernandez, R. (1996). Mapa Geológico de la Plancha 38, Carmen de Bolívar. INGEOMINAS, Bogotá.

Fettes, D., and Desmons, J. (2007). Metamorphic rocks: a classification and glossary of terms: recommendations of the International Union of Geological Sciences Subcommission on the Systematics of Metamorphic Rocks. Cambridge: Cambridge University Press. 
GEOTEC. (1997). Cartografía geológica de la Región del Sinú (Noroeste de Colombia), Planchas 50, $51,59,60,61,69,70,71,79$ y 80 (3), Bogotá.

GEOTEC. (2003). Geología de los Cinturones Sinú San-Jacinto Planchas 1:100000. 50 Puerto Escondido, 51 Lorica, 59 Mulatos, 60 Canalete, 61 Montería, 69 Necoclí, 70 San Pedro de Urabá, 71 Planeta Rica, 79 Turbo y 80 Tierra alta. Informe I20024. Memoria Explicativa. INGEOMINAS.

Guzmán, G., Gómez, E., y Serrano, B. (2004). Geología de los cinturones del Sinú, San Jacinto y borde Occidental del Valle Inferior del Magdalena, Caribe Colombiano. Instituto Colombiano de Geología y Minería, Bogotá.

Guzmán, G. (2007). Stratigraphy and Sedimentary Environment and Implications in the Plato Basin and the San Jacinto Belt, Northwestern Colombia. Ph.D. Thesis, University of Liége, Belgium.

Hallsworth, C.R., and Knox, R.W.O'B. (1999). $B G S$ Rock classification scheme. Volume 3. Classification of sediments and sedimentary rocks. British Geological Survey Research Report, RR99-3, Nottingham.

INGEOMINAS. (1997). Atlas geológico digital de Colombia. Ministerio de Minas y Energía, República de Colombia.

Kerr, A.C., Marriner, G.F., Tarney, J., Nivia, A., Saunders, A.D., Thirlwall, M.F., and Sinton, C.W. (1997). Cretaceous basaltic terranes in western Columbia: elemental, chronological and $\mathrm{Sr}-\mathrm{Nd}$ isotopic constraints on petrogenesis. Journal of Petrology, 38(6), 677-702. doi: 10.1093/ petroj/38.6.677.

Le Bas, M.J., and Streckeisen, A.L. (1991). The IUGS systematics of igneous rocks. Journal of the Geological Society, 148, 825-833. doi: 10.1144/ gsjgs.148.5.0825.

Mantilla-Pimiento, A.M. (2007). Crustal structure of the southwestern Colombian Caribbean margin. Geological interpretation of geophysical data. $\mathrm{Ph} . \mathrm{D}$. Thesis, Insitut für Geowissenschaften Friedrich-Schiller-Universität Jena. Jena, Alemania.
Montes, C., Guzman, G., Bayona, G., Cardona, A., Valencia, V., and Jaramillo, C. (2010). Clockwise rotation of the Santa Marta massif and simultaneous Paleogene to Neogene deformation of the PlatoSan Jorge and Cesar-Ranchería basins. Journal of South American Earth Sciences, 29(4), 832-848. doi: 10.1016/j.jsames.2009.07.010.

Robertson, S. (1999). BGS Rock classification scheme. Volume 2. Classification of metamorphic rocks. British Geological Survey Research Report, RR 99-02, Nottingham.

Silva-Arias, A., Páez-Acuña, L.A., Rincón-Martínez, D., Tamara-Guevara, J.A., Gomez-Gutierrez, P.D., López-Ramos, E., Restrepo-Acevedo, S.M., Mantilla-Figueroa, L.C., and Valencia, V. (2016). Basement characteristics in the Lower Magdalena Valley and the Sinú and San Jacinto Fold Belts: Evidence of a Late Cretaceous Magmatic Arc at the South of the Colombian Caribbean. CT\&F Ciencia, Tecnología y Futuro, 6(4), 5-36.

Spikings, R., Cochrane, R., Villagómez, D., Van der Lelij, R., Vallejo, C., Winkler, W., and Beate, B. (2015). The geological history of northwestern South America: from Pangaea to the early collision of the Caribbean Large Igneous Province (290-75 Ma). Gondwana Research, 27(1), 95-139. doi: 10.1016/j.gr.2014.06.004.

Streckeisen, A. (1976). To each plutonic rock its proper name. Earth-Science Reviews, 12(1), 1-33. doi: 10.1016/0012-8252(76)90052-0.

Streckeisen, A. (1979). Classification and nomenclature of volcanic rocks, lamprophyres, carbonatites, and melilitic rocks: Recommendations and suggestions of the IUGS on the Systematic of igneous Rocks. Geology, 7, 331-335. doi: 10.1130/0091-7613(1979)7<331:CANOVR $>2.0$. $\mathrm{CO} ; 2$.

Vinasco, C.J., Cordani, U., Gónzalez, H., Weber, M., and Peláez, C. (2006). Geochronological, isotopic, and geochemical data from PermoTriassic granitic gneisses and granitoids of the Colombian Central Andes. Journal of South American Earth Sciences, 21(4), 355-371. doi: 10.1016/j.jsames.2006.07.007. 
Estudio petrográfico y posibles fuentes de los clastos basales de la Formación San Cayetano hacia el sur del Cinturón Plegado de San Jacinto, norte de Colombia

\begin{tabular}{c}
\hline \hline Alejandro Silva-Arias \\
ORCID: 0000-0003-1158-4809 \\
Liliana Andrea Páez-Acuña \\
ORCID: 0000-0001-6020-6527 \\
Pedro David Gómez-Gutiérrez \\
ORCID: 0000-0002-8623-4734 \\
Daniel Andrés Rincón-Martínez \\
ORCID: 0000-0002-5684-2130 \\
\hline \hline
\end{tabular}

Trabajo recibido: marzo 08 de 2018

Trabajo aceptado: septiembre 25 de 2018 